\title{
Towards a Design Framework for Trust in Digital Civics
}

\author{
Eric Corbett \\ Georgia Institute of Technology \\ Atlanta, GA. USA \\ \{ecorbett, ledantec\}@gatech.edu
}

Christopher Le Dantec

\begin{abstract}
There is growing interest in Digital Civics regarding how trust can inform the design of technology in the civic space. Previous work has identified several key elements of trust in digital civics to consider in design such as the connection between trust and distance, trust as sociotechnical, trust as process and trust design affordances. However, these elements have not yet been applied to design. We address this gap by engaging these elements in ongoing design research within Atlanta's Department of Immigrant Affairs. Our research inquiry with the department centered on developing a design intervention to improve the department's community engagement work. We developed a design intervention with the department through co-design which was then assessed and advanced using the elements of trust. By reflecting on this design process informed through the elements, we unify the elements of trust in digital civics towards a design framework.
\end{abstract}

\section{Author Keywords}

Trust; Digital Civics; Community Engagement; Civic Technology; Digital Democracy

\section{ACM Classification Keywords}

Human-centered computing $\mathrm{HCI}$ design and evaluation methods

\section{INTRODUCTION}

Trust has become a focal point among public officials, technologists, and researchers interested in how technology can address the crisis in confidence and low participation plaguing many modern democracies [10, 16, 20]. For public officials, there is an assumption that technology can engender trust by improving both efficiency and transparency of government operation [6, 14]. For technologists, there is a belief that technology can create trust by enabling new modes of participation that afford direct citizen involvement in decision making and control [1,9]. For researchers, there is a desire to understand how trust can be understood as a design value for technology in civic life $[8,11,12]$. Despite these varied interests in trust, it remains unclear how trust can (or

Permission to make digital or hard copies of all or part of this work for personal or classroom use is granted without fee provided that copies are not made or distributed for profit or commercial advantage and that copies bear this notice and the full citation on the first page. Copyrights for components of this work owned by others than ACM must be honored. Abstracting with credit is permitted. To copy otherwise, or republish, to post on servers or to redistribute to lists, requires prior specific permission and/or a fee. Request permissions from Permissions@acm.org.

DIS '19, June 23-28, 2019, San Diego, CA, USA

(C) 2019 Association for Computing Machinery. ACM ISBN 978-1-4503-5850-7/19/06 ..\$15.00 https://doi.org/10.1145/3322276.332229 even should) be approached in the design of technology in the context of civic relationships. From a design standpoint, trust is an inherently problematic value in the civic space where cooperative actions often need to occur with partial knowledge and varying degrees of risk $[15,52]$.

In this research, we focus specifically on the work of community engagement performed by public officials in local government. Developing a better understanding of how to approach trust in the design of technology to support the work of community engagement is particularly important now for HCI as it turns to digital civics as a frame for approaching civic technology. Digital civics seeks to design systems based on developing and brokering relations between government and citizen [36]; however, if these relations are most often characterized by entrenched distrust [37, 44], how should design proceed? With this in mind, we ask: How can trust inform the design of technology used in the work of community engagement that occurs in local government? We are exploring this question in ongoing design research in the city of Atlanta's Department of Immigrant Affairs [53].

We have been working with Immigrant Affairs to explore how design interventions - informed by trust-might improve the department's community engagement practices. We approached this through a co-design intervention that included gaining a better understanding of the department's community engagement work and the unique challenges of trust present in the department's relational work with immigrant communities. We then developed a design intervention aimed at addressing some of the current challenges in their work. To guide the design work, we turned to existing elements of trust in digital civics: trust as the work of reducing distance in relationships [8], the sociotechnical nature of this work [9], the process in which trust is developed [33], and trust design affordances [7].

Through our design process, we develop and subsequently unify the individual elements towards a framework that articulates how trust can inform the design of technology used by public officials doing the work of community engagement in local government. By understanding how to design with and for trust, digital civics will be better positioned to achieve its goal of reconfiguring civic relationships [3, 51].

\section{BACKGROUND}

There are three key research areas we draw upon for this work. First and foremost, the relationship between trust and governance and how the ongoing crisis in confidence in governments of every size is affecting how communities, municipalities, and nations address matters of collective concern. 
Second is the work of community engagement and how developing trust often requires public officials to work with communities in more direct ways. Finally, the role of trust in the nascent framing of digital civics that has recently emerged in the field of human-computer interaction. Together, these areas suggest a set of common concerns, and drawing on recent scholarship, four areas through which the design of civic technologies might be informed by, and assessed on, their relationship to initiating, building, and sustaining trust-based relations between the public and governing institutions.

\section{Trust, Governance, and the Crisis in Confidence}

In local government democracy plays out through a hodgepodge of city departments that carry out every-day municipal work. This work includes functions like service provisioning, planning, building and maintaining infrastructure. It is also the work of legislation and education as well as more specialized functions like workforce and economic development. Spanning this collection of practices, responsibilities and goals within municipal work is the need for community engagement, a collection of practices performed by public officials to meet and invite the public into the process of governing [9]. In this work we focus on community engagement in the context of immigrant relations.

In the US, trust between public officials and immigrants is fraught due to the moral and legal battles over immigration unfolding throughout our government [30]. These power struggles are especially pronounced in our city, Atlanta, where the recently elected mayor, Keisha Lance Bottoms, has been outspoken in pushing back against anti-immigration rhetoric and policies from President Trump. Her administration is resisting at the local level by declaring Atlanta a sanctuary city [4]. Meanwhile, a conservative governor (strongly endorsed by Trump) who ran a "tough on immigration" campaign [14] recently won re-election [46] will likely seek to challenge the mayor's policies at the state level. Even while these larger political battles unfold, the public officials in Atlanta's Department of Immigrant Affairs continue to perform the work of community engagement: meeting and inviting new Americans into the process of governing in the city of Atlanta [53].

While trust is especially problematic in the context of immigration given the current socio-political climate [28], trust has always been problematic in the civic space [15] - now more so than ever $[44,50]$. Indeed, distrust is now so pervasive between the public and their governments, distrust is said to be a condition, if not a framework from which all inquiry into civics must begin [22]. The framework of distrust is the result of the ongoing "crisis in confidence" besetting many modern democracies [22]. The sources of the crisis are many: limitations of the state in the context of globalization [17], enduring income-equality [49], and increased skepticism toward expertise are just a few sources [50]. Taken together, these issues produce increased uncertainty and risk in society [6] which have outpaced the states' ability to respond to these complexities, resulting in eroded confidence in the state and a greater sensitivity to risk [6]. Many have noted the paradoxical and self-reinforcing nature of the present crisis: trust in government is required to enable the collective action and cooperation needed to address increasing complexity and risk in modern society [47, 49]; however, often the distrust that limits and weakens government institutions creates the opportunity and impetus for community engagement $[37,43,50]$.

Addressing the crisis requires more than immediate effort towards resolving any one particular source of distrust. Rather, it calls for a rethinking of the very nature of the relationships between the public and their government. In particular, the distance between people and their government that was originally designed into representative systems $[12,48]$ has become untenable due to the crisis [5].To reduce this distance, the onus is on public officials to "go out and get democracy" [18]. This is typically done through meeting and inviting the public into the process of governing through the work of community engagement [40]; that large category of work is typically viewed as the best response to the crisis in confidence $[13,18,40,50]$.

\section{Elements of Trust in Digital Civics}

The need to undertake a rethinking of civic relationships to address the crisis of confidence coincides with how HCI as a field has begun to turn to Digital Civics as a lens to approaching community engagement. Digital Civics is a research agenda interested in how to bring about "new configurations of government and citizenry that is relational rather than transactional" [36]. The emphasis on the relational is what most distinguishes digital civics from prior approaches to digital democracy that preceded it — as Asad et al note - this emphasis "enables us to begin to view governments (local or national) as composed through relations with constituents" [3]. Thus, rather than focusing on how design might make government efficient, or make existing modes of democratic participation more accessible, design in digital civics focuses on how to create relationships in participatory experiences between public officials and citizens based on mutual learning, empowerment and co-creation [3, 29].

Within this frame of digital civics, recent work has begun to articulate how to conceptualize and act on trust through the design and assessment of computing technologies [7, 8, 16, 19]. We identify four key elements from this prior work that we will apply and subsequently extend in our design research: distance, process, sociotechnical components, and design affordances.

We begin with the element of distance which was a key concept in our prior research to develop the notion of Trust Work which describes the work of building trust in civic relationships [8]. We identified eight practices of Trust Work which all pursued a unifying goal: to traverse various manifestations of distance. To explicate this theme of distance, we turned to the social psychology literature which has described distance as the subjective experience that something is far or close to oneself [45]. Distance research tries to understand how different perceptions of distance impacts behavior and decision making across various social situations $[27,45]$. We leveraged this literature and connected to trust 
through how uncertainty grows with distance as "something becomes increasingly distant there are more and more possible states in which that something will not materialize" [27]. Whether something will materialize (or not) gives rise to the need for trust as trust is a mechanism for dealing with the uncertainty distance introduces [26, 34].

We used this conceptualization of distance in our analysis of the role of trust in the work of community engagement [8]. We argued each dimension of distance (social, temporal, hypothetical, spatial, knowledge, power [24]) between public officials and communities presents uncertainty that trust needs to overcome. To illustrate, the work of community engagement in city planning often needs to overcome distance in the form of knowledge of planning procedures. Left unchecked, this distance leads to information asymmetry between planners and city residents that produces uncertainty (and risk) that in turn problematize opportunities for community engagement. In order to enable meaningful community engagement, city planners need to close this distance in knowledge by working to make planning procedures accessible for city residents. We adopt this previous framing of trust in this paper: understanding trust as a process of overcoming the uncertainty presented by manifestations of distance in civic relationships [8].

The next element is the process in which distances are closed through building trust over three distinct stages: initiating, building, and retaining which each require particular forms of work to close distances present [8]. These stages inform how the work of traversing distance needs to be adapted over time in order to develop trust [23]. While the stages do suggest a gradual increase of trust, the process is not necessarily linear [42]. Each measure of distance is along its own vector, so even as one area converges on trust, others might open up. The consequence is that the process of developing trust is ongoing and responsive to distances that maybe non-linear and co-occurrent. Therefore, while trust is a dynamic social construction [42]; the stages (even as approximations) are preferable for design as it hedges against the tendency to treat trust as a static value [33].

The process of closing distances enlists the third element: an assortment of sociotechnical components - the artifacts, practices, and social arrangements of a particular civic context [9]. The sociotechnical components influence each other [25]. For instance, artifacts can be created according to shifts in practices and social arrangements (i.e. body cameras made in response to distrust of law enforcement practices within minority communities). At the same time, new artifacts can lead to shifts in practices and social arrangements (i.e. civic technologies create new practices of civic participation through crowd-sourced mobile data [11]). By examining the assemblage of artifact, practice, and social arrangement, we can begin to trace how trust moves and shifts across the distances within and across the present components.

Finally, the fourth element are the four design affordances: history, experience, expectation, and preservation. These four affordances each provide guidance to how designers should interact with the challenges of each stage of the trust process. In this way, much like how affordances are popularly known throughout design practice to provide hints to how to use and interact with objects [35], these affordances are concepts for thinking about and interacting with the stages of trust development in design processes [7]. Thus, the four design affordances are generative, high-level stimulants for thinking through design decisions related to trust.

We bring this prior work to bear in design research of the work of community engagement in Atlanta's Department of Immigrant Affairs asking: "How can trust and distance, trust as sociotechnical work, trust as process, and trust affordances inform design?" Our contribution to this prior work is in gathering, applying, and developing the four elements towards a framework that articulates how trust can inform the design of technology in the civic space.

\section{METHODS AND CONTEXT}

Our approach was rooted in co-design methodology [41] and first developed an understanding of the department's community engagement work by attending a series of meetings and informal interviews with Immigrant Affairs staff. We focused particularly on revealing manifestations of distance in Immigrant Affairs' civic relationships as well as identifying salient sociotechnical components in their work practices. This initial step provided a general understanding of the work of community engagement within Immigrant Affairs. We then built from this understanding through a design activity with the department staff. We subjected the data generated from this activity to thematic clustering [31] which resulted in four themes to explore in a potential design intervention. We then assessed and advanced the design intervention using the four elements of trust: distance, sociotechnical components, process and design affordances.

\section{Department of Immigrant Affairs}

Over the course of 30 weeks, we worked with Atlanta's Department of Immigrant Affairs to explore opportunities for design interventions aimed at improving their community engagement work. This project developed from ongoing conversations with the department's director over several previous research projects we have conducted across Atlanta's local government over the past two years [7-9].

Immigrant Affairs had been in existence for three years and was chartered to serve as the voice of the rapidly growing immigrant population in Atlanta (one of the fastest growing in the US [2]). The department had five full time staff and a revolving series of interns and fellows. At the time this project was conducted, the department was in the process of building its identity - both within city hall and with the communities they engage with. Part of this identity search was the question of value: what is the value of a civic entity that does not provide quantifiable services (like public safety) or perform some direct, tangible function to the city (like planning)? In contrast, Immigrant Affairs' work is relational: the affective groundwork of establishing relationships and serving as human mediators between immigrant communities and the larger civic ecosystem of the city. In a time of austerity and growing nationalism in the US, the department faces the questions: what is the value of this relational work? 
What are the measures of impact? These questions matter as the department needs to have "evidence" to secure funding from internal sources (staff and budget allocated by the city) as well as external sources (through grants to fund specific projects) to continue to exist and grow within the milieu of city government.

To address these questions, the department expressed interest in exploring opportunities for technology to aid their mission. The assumption of the department was that technology could improve the efficacy of their community engagement work in such a way that would engender trust in the relationships between the department and the immigrant communities they engage throughout Atlanta. It is within this context we have engaged in design research with Immigrant Affairs. We approach this work from the purview of the elements of trust in digital civics in order to develop a better understanding of how trust could inform the design technology to support Immigrant Affairs' work of community engagement. In what follows, we discuss the ethnographic insights we developed working with the department which set the space of our design inquiry.

\section{Community Engagement in Immigrant Affairs}

The mission of Immigrant Affairs is to make the city more inclusive by ensuring new Americans are fully engaged in all the opportunities the city offers. Mariah, the director of the department, describes the challenge for trust in carrying out this mission: "We work in communities where the police force, which is a part of city government, might not have a great relationship with the community. We work in those areas where they do, or we go in a lot of places where it's perception of what the government does and what the government's interests are versus the realities of that, whether that mistrust is real or perceived is very much a thing." Problematic relationships with law enforcement as well as generalized mistrust of government characterize the social reality for many communities Immigrant Affairs must engage. Therefore, despite the goodwill of the staff (many whom are themselves immigrants), Immigrant Affairs is still a government entity. As such, their work of community engagement often occurs from a default position of suspicion if not outright distrust. Given this condition, the department must cultivate their own relationships in order to achieve their larger goal of closing various manifestations of distance between the city government and immigrant communities.

\section{Distance and Trust}

The department's work of closing distances is exemplified by CitySpeaks: a cultural competency and accessibility initiative Immigrant Affairs recently developed that provides training and guidance to city employees across the different entities in city hall on the best practices and policies for interacting with immigrant communities. In this way, CitySpeaks attempts to close social distance by making the city more socially amenable to those of different cultures and languages. "You shouldn't have to speak English to interact with City Hall..." Mariah remarked citing the 14th amendment as the basis for why the department developed this program.
CitySpeaks reflects the department's internal facing work of improving civic accessibility. However, knowing where and what accessibility issues exist requires the department to proactively build and maintain relationships with immigrant communities through fieldwork. Immigrant Affairs spends a great deal of time in the field having open-ended conversations. This fieldwork closes social distance by 'Meeting People Where They Are' [8] in parks, groceries stores, setting up tables at events, etc. Conversations within this ongoing fieldwork enable the department to be both open and reactive in learning where and when new programs or services need to be created or repaired (such as CitySpeaks). In this way, Immigrant Affairs' fieldwork attempts to initiate the process of developing trust with immigrant communities. The interactions during fieldwork often lead to the development of initiatives like the Morius Mill Issue.

Morius Mill was an apartment complex heavily populated with undocumented Mexican immigrants. During fieldwork, residents of the apartment started a conversation with Immigrant Affairs about the horrid conditions they were facing in the apartments: mold, insect and rodent infestation, and lack of cooling and heating to name a few of the attributes of the apartment. The property management refused to address the decrepit conditions and seemed to be leveraging the resident's fearfulness of reaching out to the city or other legal remedies because of their immigration status. Indeed, this was the result of distance in power that prevented the residents from taking action against the property managers. The department is taking a two-prong approach to close this distance: on the ground, they worked to address the barriers preventing residents to file code violation complaints; within the city, they leveraged different legal mechanisms from the city's housing authority to force the property management to comply. This work typifies Immigrant Affairs as a department: carrying out the affective groundwork to establish relationships with the residents of Morius Mills to ensure them of their rights to hold the apartment management accountable and then assisting the residents with navigating the civic ecosystem necessary to take action.

\section{Sociotechnical Tensions}

The department's existing technology use plays a very marginal role in supporting their community engagement work for several reasons. First is accessibility: while a large amount of the immigrant communities they interact with do have smart phones, many do not utilize the full range of features (emails, apps, etc.) Additionally, the department utilizes various social media platforms such as Instagram, Facebook, and Twitter for marketing events or posting informational content. However, the reach of these platforms is limited as Fernando, the assistant deputy director, described: "the people we interact with on twitter are already engaged, they are not the real community."

Beyond accessibility, perhaps the biggest challenge is the fundamental mismatch between Immigrant Affairs' work and the affordances of technology. To illustrate, addressing the Morius Mills issue relied heavily on the development of trust between the department and the residents through 
relational work which primarily takes the form of openended conversations occurring face-to-face. While essential to developing relationships, the qualitative nature of this work sets up a tension with the need to generate and work with data.

The quantification of immigration, the need to know where and when and how many people are and are not, is what drives work and resources. As Mariah points out: "We want to serve so many people, in so many ways. But to really identify the issues and be really strategic about how we want to address those issues and in that strategy have it be about where do we have the biggest impact with our limited resources. Because unfortunately, any government or community organization will say the scope of the problem outweighs the resources that we have. So how do we use our limited resources to really effectively have the most impact?" As Mariah expresses, there is clearly a need for quantitative data in Immigrant Affairs' community engagement work to inform vital strategic insights; however, their relational work is not readily quantified or captured. Indeed, how does one quantify the development and operationalization of trust in the Morius Mills Issue?

Thus, the primary challenge for our design research is resolving the tensions between on one hand, understanding how technology can support Immigrant Affairs' work of closing distance between immigrant communities and the civic system. This requires 'Trust Work' (meeting people where they are, having face-to-face conversations, developing interpersonal and institutional relationships [8]) which is not readily supported by the technological artifacts at the department's disposal. And on the other hand, leveraging the advantages that technology affords (the ability to quantify, collect, and work with data) which could serve to improve the overall function of the department. To explore this sociotechnical tension in design, we focused on the concept of touch points.

\section{Touch Points}

A salient theme in our analysis of Immigrant Affairs' community engagement work was the concept of touch points: the various interactions Immigrant Affairs creates and maintains with immigrant communities through community engagement. Figuratively, the department works to "touch" as many immigrant communities as possible through their community engagement work: the fieldwork conversations, social-media outreach, etc. Ideally, this work closes distance enabling a civic relationship wherein immigrants feel comfortable to in return "touch" their city. From the lens of digital civics, touch points reflect "the myriad of relations with constituents that matter most in day-to-day civic life" [3] that digital civics seeks to create and support through technology $[36,51]$. Mariah recalled her observation of such relationships coming into existence when residents of Morius Mills attended the opening of a new city park adjacent to the apartment complex: "these people didn't even know who we were not too long ago so for them to show up on this rainy Wednesday morning, Facebook living the mayor.... being super into this [civic event] is really amazing." Mariah credited the Morius Mills community presence at this event largely as a result of the department's work to develop relationships with the community. Mariah is emphasizing the importance of relational civic encounters but from the standpoint of trust, "how many touches" Mariah wondered-does it take to establish such relationships?

Building from this conceptualization, we proposed exploring a design intervention centered around the concept of touch points. We saw touch points as a concept that could encompass many of the issues identified in our initial analysis (the need for data, building relationships, opportunities for technology, quantification of trust, etc.) To do so, we conducted a co-design activity with the department. The activity focused on exploring how a design intervention might enable Immigrant Affairs to capture, visualize, and interact with touch points. By focusing on touch points, the activity provided an opportunity to explore to explore the sociotechnical mechanisms that might support and enable the relational work of the department.

\section{Co-Design Activity}

The activity was attended by all staff (aside from Mariah) in a conference room at City Hall and lasted approximately two hours. Data collected from the activity included: audio recording, ethnographic field notes, and a series of design concepts expressed in paper wireframes.

The first part of the activity was touch-point mapping. On two large papers, we instructed the department to list all existing touch points (those the department currently has access to) as well as desired touch points (those the department would like to have access to). We further instructed them to distinguish between outgoing touch points (interactions initiated by the department like conversations in fieldwork) and incoming touch points (interactions initiated by constituents i.e. someone coming to a citizenship information session). This mapping activity produced 64 touch points.

The touch points were articulated in variety of ways. For instance, some of the existing touch points took the form of communications mediums: local news channels, Twitter, text messages, flyers, fieldwork conversations, etc. Others took the form of events and programs such as the department's annual soccer festival, citizenship information sessions, or local community events. Desired touch points followed a similar pattern. Some took the form of communication mediums: a web page for constituents to enquire about services, a department newsletter, billboard advertisements. While others described particular ethnic groups: Middle Eastern, Asian, Caribbean, etc.

The touch point mapping activity highlights two of the trust elements we are engaging: distance and sociotechnical components. The element of distance comes to mind in how the ethnic groups the department listed as desired touch points reflect that these relationships are distant - that work will be needed to establish these relationships. Additionally, the variety of ways the touch points were articulated point to the sociotechnical element: some points were social arrangements (relationships with particular ethnic communities), while others were practices (holding events and programs) 

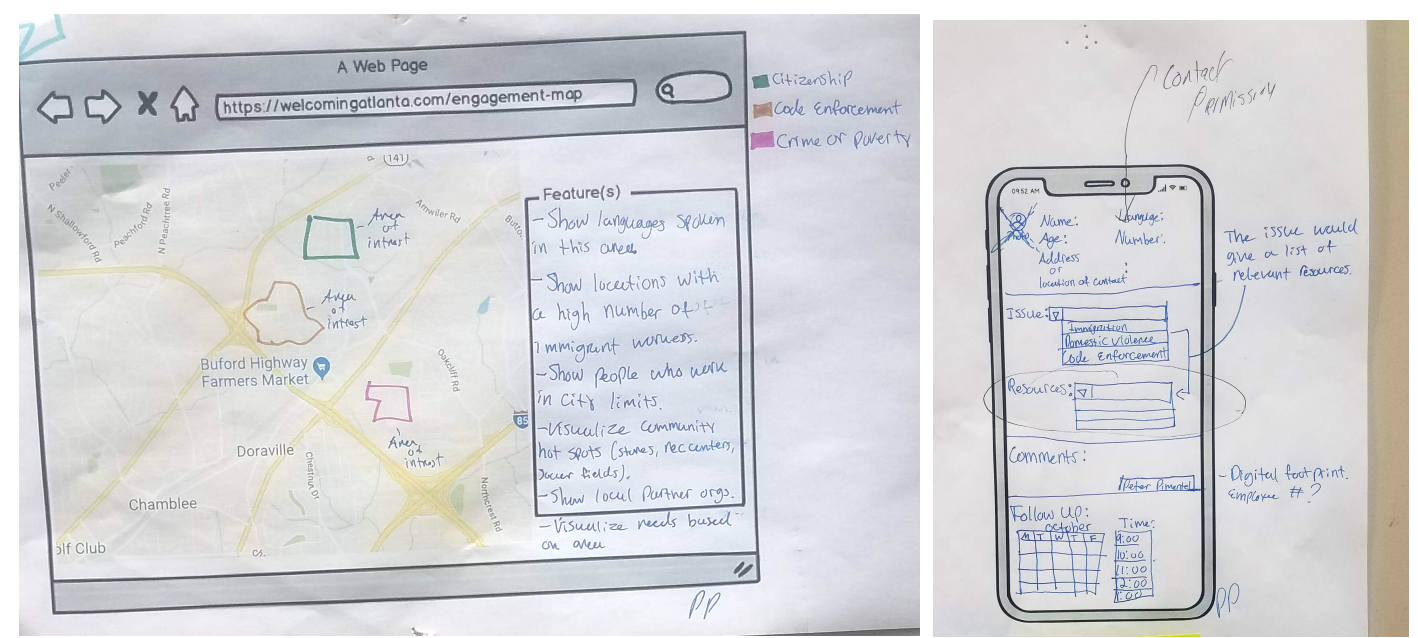

Figure 1. Design concepts from the participatory design activity. (A)The left concept was one of 15 in the Data Based Decision Making theme. This particular concept is an information visualization of various demographic and issue-based data in areas of interest for Immigrant Affairs. (B) The right concept was one of 4 in the Initial Touch Point Interactions theme. This particular concept is a mobile application to capture salient elements of fieldwork conversations.

or artifacts (non-digital like flyers or digital like Twitter).

In the next portion of the activity, the participants were instructed to explore possible interactions with the touch points using technology: "imagine that we had all of these touch points...if you could interact with those touch points digitally. What would that look like, at different scales?" To facilitate, we provided blank paper map mock-ups of different areas of the city Immigrant Affairs works in for them to draw and explore different ways of interacting with touch points (blanks of Figure 1-A).

The final part of the activity involved exploring how Immigrant Affairs might capture touch points using technology. They were instructed as follows: "imagine you had an Immigrant Affairs app on your phone that was specifically designed for capturing these touch points... What would that look like?" To facilitate, we provided blank mobile phone, tablet, and website wire frames to explore different interactions for capturing touch points (Figure 1-B).

In all, the activity generated 34 concepts which were thematically grouped into four themes [31]: Initial Touch Point Interactions, Existing Touch Point Interactions, Data Based Decision-making, and Inter-Organizational Accountability. In what follows, we describe each theme in turn and then engage them collectively as the basis for a design intervention which we will explore using the elements of trust.

\section{Initial Touch Point Interactions}

The four concepts in this theme involve initial interactions with touch points. These concepts were envisioned as features of a tablet or mobile phone app (similar to Figure 1-B). For instance, one concept was a digital intake form on a tablet device to collect demographic information during Immigrant Affairs' programs. Another concept was a mobile app Immigrant Affairs staff could use during fieldwork. The mobile app was envisioned to record the details of fieldwork conversations and collect demographic data. The salient elements of the conversation would be captured with a dropdown menu with a list of common issues (i.e. citizenship, law enforcement, public safety, etc.) to categorize the nature of the conversation. Another concept also described for the fieldwork app was a service recommendation feature that uses the demographic data and issue type entered into the app to suggest services or resources in real time. The value of the concepts in this theme reflects Immigrant Affairs desire to improve their fieldwork interactions. Despite the centrality of these initial interactions, Immigrant Affairs has no system for collecting or organizing the data from these conversations therefore making it difficult to operationalize later on in their work.

\section{Existing Touch Point Interactions}

The concepts in this theme describe interactions with existing touch points (i.e. those gathered from interactions in the previous section). With touch points captured, Immigrant Affairs envisioned various concepts to facilitate further interactions with these existing points. These concepts all took the form of a map interface that would visualize collected touch point data from different areas within the city. For instance, all of the touch points from Morius Mills community could be visualized on a map interface. With this data surfaced on the interface, another concept was envisioned to send mass texts or robo-calls to remind/update residents on progress with resolving ongoing issues. Relatedly, another concept would automatically translate these outgoing communications to different languages. The concepts in this theme reflect Immigrant Affairs desire to improve the efficiency of their work. Given the limited human resources of the department, managing communication efficiently is vital.

\section{Data-Based Decision-Making}

The concepts in this theme describe desired interactions with and through data to inform decision making. Similar to the previous section, these concepts took the form of data visualizations on a map interface (Figure 1-A). However, the concepts in this theme were not limited to existing touch points. Rather, these concepts envisioned interactions with a wider variety of data. For instance, one concept was envisioned to be able to discover pockets of unaccounted for 
residents (victims of unreported crimes and undocumented immigrants). In reality, no such data exist as undocumented immigrants are largely invisible to the systems that would collect such data - once again reiterating the challenge of engaging undocumented residents. Likewise, several other concepts were envisioned to reveal local assets that Immigrant Affairs could leverage: community hot-spots like groceries stores frequented by immigrants or local immigrant friendly businesses or community organizations.

Several concepts were envisioned to visualize the demographics of areas of interest to the department: areas with high levels of racial and language diversity, low-income, and large family sizes. Such data would feed into decision making capacities described in other concepts such as knowing where language assistance might be needed or where families living below the poverty line may need government support. Likewise, another concept was envisioned to visualize needs based on area: where citizenship training should be held, where there are code enforcement issues, or areas with high crime and poverty.

The concepts in this theme reflect the value of data for Immigrant Affairs' community engagement work. As described earlier, much of the challenge for Immigrant Affairs is simply not knowing where and how to reach immigrants (especially the undocumented). Much of their work is essentially filling in these gaps through community engagement. In essence, making these communities visible and thus legible to the civic system.

\section{Intra-Organizational Accountability}

The concepts in this theme describe interactions to improve internal accountability within the department. This theme was distinct in how the concepts described were all directed inwards to improve or augment workplace practices rather than external facing interactions with communities. For instance, there were multiple concepts that described creating and assigning "cases" to staff as well as remind staff to follow-up with ongoing cases. A case might be created based on the need to document and track the status of an ongoing interaction with a constituent (i.e. progress with resolving issues throughout Morius Mills). Another concept was envisioned to visualize ongoing and completed cases in different areas of the city on an interactive map interface. Such a visualization would allow a high-level view of the efficacy of the department's efforts across case types in different areas of the city.

The concepts in this theme reflect a desire for Immigrant Affairs to use technology as means to self-enforce accountability. Currently, the department appears to function in a very ad-hoc, free-flowing manner. As a relatively new department, this is expected to some extent, but it also seems to be a style of management that works best for the largely unstructured, reactive nature of their work (i.e. the ad-hoc nature of addressing the Morius Mill issue).

\section{USING THE TRUST ELEMENTS}

Collectively, the four themes articulate features of a community engagement platform for Immigrant Affairs. The platform would feature the following components: a mobile phone application for fieldwork, a tablet-based intake sheet, a map interface with various data-visualization capabilities, and a workflow management system. Through these features, the platform would facilitate a wide array of interactions with various touch points. We now bring the elements of trust in digital civics we reviewed in the background section (distance, sociotechnical components, process and design affordances) into conversation with the envisioned platform. How can the design of the platform be informed by these elements?

The first element, distance, suggests the overall and primary goal of design should be to develop features and affordances that would support closing distance. From this element we pose the following question: How can the platform be designed to close different manifestations of distance in the civic relationships between Immigrant Affairs and the communities they work to engage? The second element suggests that design needs to take a sociotechnical approach to closing distances by considering the interplay of three components in the design space: artifacts, practices, and social arrangements. From this element we pose the following question: How can the sociotechnical components be designed (or redesigned) in order to reduce distances? The third element process suggests that design needs to consider the ways in which the platform might facilitate the reduction of distances over time. Thus, from this element we posed the following question: How can the platform be designed to support the process of trust development across the stages of initiating, building, and retaining?

With the design space set from the questions informed by the first three elements, we utilized the design affordances - history, experience, expectation, preservation - to consider the ways in which the particularities of trust inscribed within each affordance could guide how we approach the challenges presented by the questions.

\section{History}

The first affordance, history, foregrounds trust as a process that is future orientated yet forged from the history of distance in social arrangements [7]. For this reason, history as an affordance is important to consider in the initiating stage as it grounds the process of traversing distances within the history that has produced them. To illustrate, immigrant communities often either lack any history with the American civic system (manifesting distance as knowledge) or have had problematic histories with other civic entities (manifesting distance as social familiarity). An ahistorical approach in design - either ignoring or discounting these experienceswould hinder the process of initiating trust. From this perspective, the affordance of history sensitizes our design work towards considering how the platform can initiate the trust process within the history of past experiences. The features in the Data-Based Decision-Making theme speak to history. The ability to surface data about communities' experiences - the hardships they might have faced like unreported crimes, code violations, or problematic interactions with other civic entities - sets the stage to develop empathy. Of 


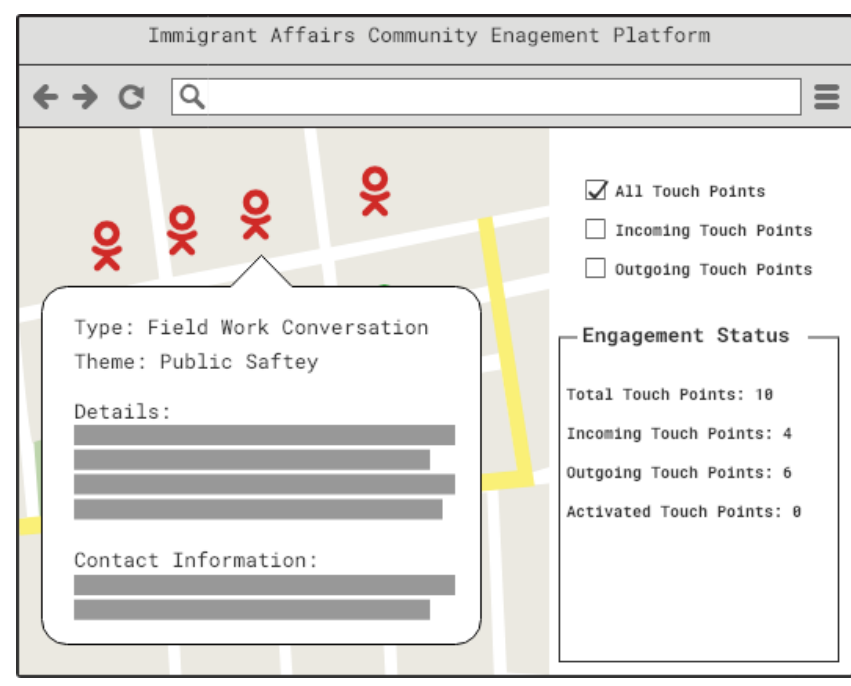

Figure 3. Mockup of interactive touch point map. The highlighted red touch is displaying information collected during fieldwork.

course, having data about history and empathizing with the experiences of those who have lived it are not the same-but nonetheless having that data and operationalizing it in decision making conveys a level of goodwill that is vital to initiating the process of trust. In this way, the Data-Based Decision-Making concepts can be made to augment the face-toface work in Initial Touch Point Interactions by providing the basic building blocks for developing empathy. Beyond past experiences, the platform should also support the work of establishing history for the civic relationships between the department and immigrant communities to reference and thus grow from. To do so, the platform should enable the collection and documentation of touch data through the concepts described in the Initial Touch Point Interactions theme. To accomplish this, the platform should allow fieldworkers to record a touch point in a lightweight manner on their mobile device. These touch points would be visualized on an interactive map: green markers would indicate an incoming touch point whereas red would be used for outgoing (Figure 3.) The app would have predefined categories (e.g. Public Safety, Economic Development, Community Engagement) that the fieldworker would select then enter a description of the salient elements of their conversation within the selected category. This will allow the fieldworker to reduce and capture the stories in such a manner that will allow data to be collated and compared in a collective data-set. For each touch point, the fieldworker could also record information regarding when, where, and with whom the conversation took place.

\section{Experience}

The second affordance, experience, calls attention to how trust as a process develops over time only through the accumulation of experiences [7]. It is both the opportunity for and quality of experience that eventually reduces distances. Therefore, experience as an affordance is important between the initiating and building stages as it focuses sociotechnical work towards creation of experiences that can build upon the trust that has been initiated. To illustrate, it was only through the experiences of interacting with the Morius Mills residents

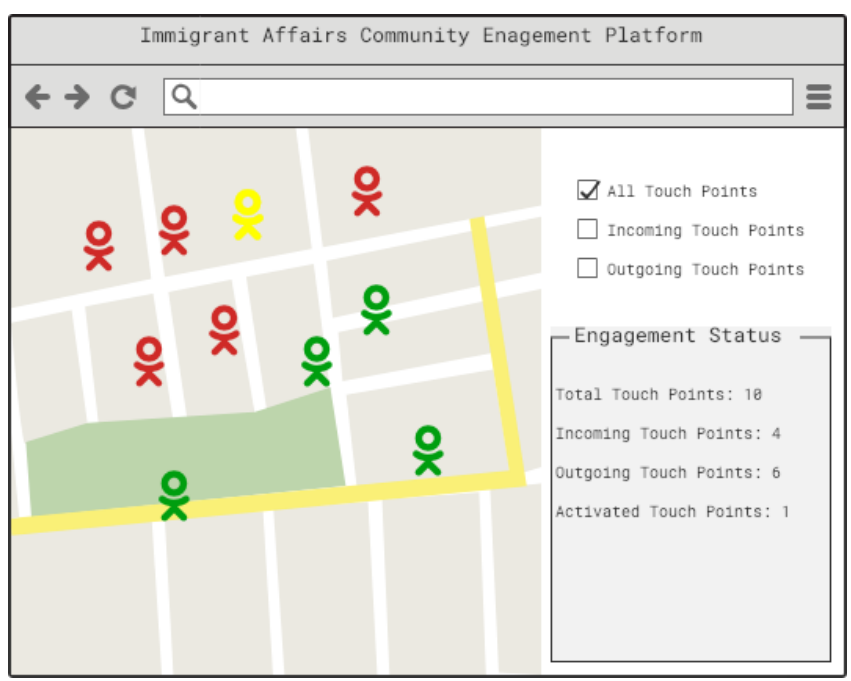

Figure 4. Mockup on interactive touch point map with process concept. The previously red touch point has changed to yellow to indicate an ongoing interaction.

over time that enabled the department to build trust. Indeed, experiences that are ongoing, continuous and frequent are the building blocks for trust. From this perspective, experience sensitizes our design work towards considering how the platform might enable ongoing experiences.

Building trust requires that both trustee and trustor have opportunities to interact in a bi-directional manner; it is not enough to meet someone where they are and record a data point. Furthermore, it would also be inadequate from the standpoint of experience for the platform only to support one-way communication. Therefore, the affordance of experience suggests the platform should enable bi-directional interactions. Given the preference of text and phone-based interactions within the immigrant communities the department interacts with, the platform should contain an interface to manage texts and phone calls as envisioned through the concepts in the Existing Touch Point Interaction theme. The department could have a designated phone number for communication through the app. If the fieldworker collects a phone number from a conversation with a constituent, the constituents' phone number would be attached to that touch point data. Additionally, the fieldworker would give the department's phone number to the constituent. Then, if this existing touch point contacts the department anytime in the future, the existing marker on the map is changed (from red to yellow) to indicate this is an ongoing interaction (Figure 4). This would allow additional tracking of incoming and outgoing touch points: a new incoming call or text to the department's phone number from constituents would create an incoming touch point marker (green marker) within the app whereas if the incoming call or text is from an already existing touch point, the color of the existing touch point updates (from green to yellow). Likewise, an outgoing call or text from department staff would also update the marker (from red to yellow). The yellow touch points are thus "activated" on the interface to indicate bi-directional interaction. The interactive touch point map could further support the ongoing interactions needed for trust to develop as a process by being live, 
rather than static. To achieve this, touch points would only be visible for a certain amount of time. Therefore, after a period of time the touch point marker on the map would dim then eventually disappear from view. While the map would contain a feature to view the history of touch points, the point is to indicate (and reinforce) the need for ongoing interaction with touch points.

\section{Expectation}

The third affordance, expectation, frames trust as a process that is fundamentally about how expectations are formed and maintained [7]. Indeed, trust can be defined as the process of how one comes to form positive expectations in the face of uncertainty [32]. As such, the affordance of expectation is especially important between the building and retaining stages as it emphasizes the need to maintain and support expectations over the process of reducing distances. To illustrate, in order to progress trust development in the Morius Mills issue, the department needed to first enable positive expectations with the residents about how they would address the issues being faced and then follow with maintaining these expectations as the work unfolded. Undoubtedly, this work will face setbacks, delays, and failures which may call into question whether or not the issues will ever be addressed-manifesting hypothetical distance - the sense of how likely an event or idea will occur. From this perspective, expectation sensitizes our design work towards considering how the platform might mediate setting and maintaining expectations.

The platform could support setting expectations through including a feature in the fieldwork application envisioned in the Initial Touch Point theme which would automatically schedule a follow-up contact from staff. Such a feature would enable expectations that this initial contact is not a one-off engagement; but rather the beginning of a civic relationship with the department. After setting these expectations, the communication features in the Existing Touch Point Interactions theme provide the means necessary to maintain expectations. By being able to speed up the mundane work of translating communications across multiple language and send batch messages, the limited human resources of the department - which otherwise might hinder maintaining expectations - is reduced.

The platform could further maintain expectations through the features within the Intra-Organizational Accountability theme. For instance, the features to remind staff to follow-up with ongoing cases. Indeed, a key part of maintaining expectations for trust is accountability and reliability. The department seems to be aware of this by envisioning such concepts in the Intra-Organizational Accountability theme. This reflects an understanding that even though the staff works from a position of goodwill and honest desire to help immigrant communities; goodwill alone is not enough. Their goodwill must be coupled with the ability to address issues like Morius Mills which requires intra-organizational accountability. Through this accountability, the positive expectations necessary to develop and maintain trust are afforded.

\section{Preservation}

The fourth affordance, preservation, highlights the need to prevent the gradual loss of trust over time through the work of preserving relationships [7]. For this reason, preservation as an affordance is most relevant to the retaining stage as it addresses how relationships established over the course of the trust process can be preserved. To illustrate, the department, having developed trust with the Morius Mills residents, was aware for the need to preserve these relationships. They are currently planning to regularly host events at the park opened across from the apartments described earlier. From this perspective, preservation sensitizes our design work to consider how the platform might aid in retaining trust in relationships over time.

For preservation, we should distinguish between two forms of relationships in social arrangements-institutional (relationships with Immigrant Affairs as a department) and interpersonal (relationships with staff). Trust is ultimately a product of both relationship types - but the ways in which trust operates through the two are distinct. For instance, much of the ground work in Morius Mills was performed by one staff member (a recent graduate from a local college) who is considering leaving the state to pursue graduate school. Thus, trust here is largely mediated through the interpersonal relationship with this staff member. Indeed, the earlier remarks by Mariah regarding the attendance of the Morius Mills residents at the park opening were attributed specifically to this staff member. While the current size of the department makes it easy to share these experiences now, as the department expands, it will become important for these interpersonal touch points to be subsumed into institutional relationships in order to achieve preservation of the trust established.

Many of the features envisioned across the previous three affordances can aid in preservation of institutional relationships. For instance, the creation of community engagement data through the concepts within the Initial Touch Point Interactions theme as well as the creation of cases in the IntraOrganizational Accountability theme both enable institutional memory that is vital to preservation [1]. As it is now, much of the memory of these interactions are distributed across the interpersonal relationships the individual staff members hold with the segments of communities they work within. This is problematic for preservation as staff will cycle over time.

While collecting touch point data and the creation of cases afford the creation of institutional memory - the form this data needs to take to accomplish preservation will be important. A data-base of "facts" cannot adequality transfer the emotions and experiences of these relationships. This points to the need to design a digital artifact - an archive of sortsthat would capture and convey the affective qualities within the many personal connections the department makes during fieldwork. Such an archive could be used to onboard new department employees or shared with the public through digital media in order to preserve a commitment to the many relationships built through the department's work of community engagement. 


\section{DISCUSSION}

Our research within Atlanta's Department of Immigrant Affairs explored a design intervention to improve the department's community engagement practices. The contribution of this paper is the use of the four elements of trust to guide our design process. We end by reflecting on our design process and use of the elements, pointing to how they can be construed as a design framework to address the specific challenges of creating systems that support civic relations. The four elements - distance, sociotechnical components, process, and the design affordances - work together to provide an initial analytic frame for understanding civic work practice, and then shift to a generative frame for creative interventions into that practice such that enactments of trust remain central. We present the framework as a four-step design process.

The element of distance can be used as a heuristic to organize local manifestations of distance in civic relationships. Trust is idiosyncratic, so the ways in which distance will manifest will vary across different relationships and context [32].To illustrate, our analysis revealed that issues with language and cultural accessibility of city services manifest social distance between Atlanta's government and immigrant communities. This social distance-coupled with problematic relationships with law enforcement and the legal hardships of being undocumented-likely manifested the distance in power present in the Morius Mills issue. Given this situated nature of distance, we suggest similar a perspective to what Le Dantec et al once argued for in approaching the values in Value Sensitive Design practice, that distances should be discovered in situ "as local phenomena, expressed in a local vocabulary" [10]. Such a perspective is vital as distance and trust will always be the product of a local ecology: the interactions between artifacts, practices, and social arrangements in a particular place and time [8]. Thus, the first step should be: $\boldsymbol{R} \boldsymbol{e}-$ veal Local Manifestations of Distance.

In addition to revealing local manifestations of distance, it will also be necessary to the identify relevant sociotechnical components: how do existing practices, artifact use, and social arrangements within and outside of city government perpetuate distances (or reduce them)? To illustrate, our analysis found tensions between the department's qualitative practices and potential uses of data afforded by technological artifacts. This tension highlights the interplay between the components which emphasizes the need for the design space to encompass artifacts, practices, and social arrangements as an assemblage - suggesting the utility of an actor network type perspective [21]. A sociotechnical understanding of trust hedges against the tendency to focus exclusively on technology and the reflex to technological determinism [54]. Rather, the sociotechnical perspective realizes that "trust cannot be designed into a system" as the trust HCI scholar Riegelsberger once remarked; however, "designers can aim to create optimal environmental conditions for the emergence of trust, but they cannot fully determine users' behavior" [39]. Thus, the second step should be: Identify Relevant Sociotechnical Components.
The distances and sociotechnical components identified in the previous two steps can be further explicated using design. To illustrate, the co-design activity we conducted with Immigrant Affairs staff revealed the personal desire to use to technology as a means of enforcing practices of intra-organizational accountability onto the department. In this way, much like Ratto described in critical making, the design activity served as a "way to begin to understand the importance of personal investment in linking conceptual understandings of technology's potential to everyday experience" [38]. Indeed, the physical activity of making the paper prototypes enabled insights regarding accountability that were not evident through our initial ethnographic analysis alone. This illustrates how design as a mode of inquiry [55], can further insights of both distances and sociotechnical components. Thus, the third step should be: Explore Distances and Sociotechnical Components using Design.

With the design space shaped through the previous steps of identifying local manifestations of distance and relevant sociotechnical components, the third and fourth elements of process and design affordances shift to generative design. Process serves as a heuristic for identifying features and affordances that would support the process of reducing local distances. The design affordances come into play to focus design decisions towards addressing the particularities of progressing the trust process. Taken together, these two elements aid in abductive sense-making in design synthesis [20]. Specifically, in the process of "Insight Combination" where after initial design insights are articulated (i.e. the four themes from the design activity), these insights are then forced into a structured pairing with existing design knowledge (i.e. the four design affordances and process stages). This pairing "creates a new design idea that has a strong connection to both established best practices and to problem-specific research data" [20]. Using process and design affordances rooted in an understanding of trust creates bright-lined connections back through sociotechnical components and distance in order to support relational civic interactions. Thus, the fourth step should be: Generate using

\section{Process and Design Affordances.}

\section{CONCLUSION}

In this work, we reviewed, utilized, and unified existing elements of trust in digital civics through our ongoing design research into the work of community engagement in Atlanta's Department of Immigrant Affairs. Through this research, we have been able to construct a framework for trust in the design of systems that support digital civics. Our framework illustrates how to operationalize trust in the design of technology used in the work of community engagement. By orientating design around the need to overcome distances in civic relationships, we can focus on trust as achieved through a process of sociotechnical work that is guided by the affordances of history, experience, expectation, and preservation. Advancing this framework is urgent work to inform how both the civic technology industry and the growing digital civics agenda within HCI might address the crisis in confidence and subsequent distrust throughout civic relationships. 


\section{ACKNOWLEDGMENTS}

We are grateful to our partners in the City of Atlanta's Department of Immigrant Affairs. This project was supported by the NSF under grant IIS-1524380.

\section{REFERENCES}

[1] Ackerman, M.S. 1998. Augmenting organizational memory: a field study of answer garden. $A C M$ Transactions on Information Systems (TOIS). 16, 3 (1998), 203-224.

[2] ARC Regional Snapshot: Growth is Strong in Metro Atlanta's Hispanic and Latino Communities - ARC: 2018. https://atlantaregional.org/news/workforceeconomy/arc-regional-snapshot-growth-strong-metroatlantas-hispanic-latino-communities/. Accessed: 2019-01-20.

[3] Asad, M., Le Dantec, C.A., Nielsen, B. and Diedrick, K. 2017. Creating a Sociotechnical API. Proceedings of the 2017 CHI Conference on Human Factors in Computing Systems - CHI '17 (2017), 2295-2306.

[4] Atlanta calls for ICE to move its detainees out of the city jail: 2018. https://www.ajc.com/news/state-regional-govt--politics/atlanta-calls-for-ice-move-itsdetainees-out-the-cityjail/s2FAuYLosJfRRyqVTsWvHO/. Accessed: 201901-27.

[5] Barber, B. 1983. The Logic and Limits of Trust. Rutgers University Press.

[6] Beck, U. 1992. Risk society: Towards a new modernity. Sage.

[7] Corbett, E. and Le Dantec, C.A. 2018. Exploring Trust in Digital Civics. Proceedings of the 2018 on Designing Interactive Systems Conference 2018 - DIS '18 (2018), 9-20.

[8] Corbett, E. and Le Dantec, C.A. 2018. Going the Distance: Trust Work for Citizen Participation. Proceedings of the 2018 CHI Conference on Human Factors in Computing Systems (2018), 312.

[9] Corbett, E. and Le Dantec, C.A. 2018. The Problem of Community Engagement: Disentangling the Practices of Municipal Government. Proceedings of the 2018 CHI Conference on Human Factors in Computing Systems (2018), 574.

[10] Le Dantec, C. a., Poole, E.S.E.S. and Wyche, S.P.S.P. 2009. Values as lived experience: Evolving value sensitive design in support of value discovery. Proceedings of the 27th international conference on Human factors in computing systems (CHI '09). (2009),

1141-1150. DOI:https://doi.org/10.1145/1518701.1518875.

[11] Le Dantec, C.A., Asad, M., Misra, A. and Watkins, K.E. 2015. Planning with crowdsourced data: rhetoric and representation in transportation planning. Proceedings of the 18th ACM Conference on Computer
Supported Cooperative Work \& Social Computing (2015), 1717-1727.

[12] Federalist Papers No. 51 - Bill of Rights Institute: 1788. https://billofrightsinstitute.org/foundingdocuments/primary-source-documents/the-federalistpapers/federalist-papers-no-51/. Accessed: 2019-0102.

[13] Fledderus, J., Brandsen, T. and Honingh, M. 2014. Restoring Trust Through the Co-Production of Public Services: A theoretical elaboration. Public Management Review. 16, 3 (2014), 424-443. DOI:https://doi.org/10.1080/14719037.2013.848920.

[14] Ga. governor candidate's ad says his truck is for rounding up illegals: 2018. https://www.usatoday.com/story/news/nation/2018/05/ 10/brian-kemp-illegals-ad/600212002/. Accessed: 2019-01-27.

[15] Hardin, R. 1999. Do we want trust in government? Democracy and trust. (1999), 22-41.

[16] Harding, M., Knowles, B., Davies, N. and Rouncefield, M. 2015. HCI, Civic Engagement \& Trust. Proceedings of the 33rd Annual ACM Conference on Human Factors in Computing Systems - CHI '15. (2015), 2833-2842. DOI:https://doi.org/10.1145/2702123.2702255.

[17] Held, D. and McGrew, A. 1993. Globalization and the liberal democratic state. Government and opposition. 28, 2 (1993), 261-288.

[18] King, C.S., Feltey, K.M. and Susel, B.O. 1998. The question of participation: Toward authentic public participation in public administration. Public administration review. (1998), 317-326.

[19] Knowles, B., Harding, M., Blair, L., Davies, N., Hannon, J., Rouncefield, M. and Walden, J. 2014. Trustworthy by design. Proceedings of the 17th ACM conference on Computer supported cooperative work \& social computing - CSCW'14. (2014), 1060-1071. DOI:https://doi.org/10.1145/2531602.2531699.

[20] Kolko, J. 2010. Abductive Thinking and Sensemaking: The Drivers of Design Synthesis. Design Issues. 26, 1 (2010), $15-28$. DOI:https://doi.org/10.1162/desi.2010.26.1.15.

[21] Law, J. and Hassard, J. 1999. Actor network theory and after. (1999).

[22] Levine, C.H. 2015. Citizenship and Service Delivery. The age of direct citizen participation. 44, (2015), 78.

[23] Lewicki, R.J., Tomlinson, E.C. and Gillespie, N. 2006. Models of interpersonal trust development: Theoretical approaches, empirical evidence, and future directions. Journal of Management. 32, 6 (2006), 991-1022. DOI:https://doi.org/10.1177/0149206306294405.

[24] Liberman, N. and Trope, Y. 2014. Traversing 
psychological distance. Trends in Cognitive Sciences. 18, 7 (2014), 364-369. DOI:https://doi.org/10.1016/j.tics.2014.03.001

[25] Lievrouw, L.A. 2014. Materiality and media in communication and technology studies: An unfinished project. Media technologies: Essays on communication, materiality, and society. (2014), 2151 .

[26] Luhmann, N. 1979. Trust and Power. Wiley.

[27] Maglio, S.J., Trope, Y. and Liberman, N. 2013. The Common Currency of Psychological Distance. Current Directions in Psychological Science. 22, 4 (2013), 278282. DOI:https://doi.org/10.1177/0963721413480172.

[28] Marisa, A. and Backlash, H.Z.L.W. 2015. Immigration, Race, and American Politics. Princeton, NJ: Princeton University Press.

[29] McCarthy, J. and Wright, P. 2015. Taking [A]part. MIT Press.

[30] McHugh, M. 2018. In the Age of Trump: Populist Backlash and Progressive Resistance Create Divergent State Immigrant Integration Contexts. Washington, DC: Migration Policy Institute.

[31] Miles, M.B., Huberman, A.M. and Saldana, J. 1984. Qualitative data analysis: A sourcebook. Beverly Hills. (1984).

[32] Mollering, G. 2006. Trust: Reason, Routine, Reflexivity.

[33] Möllering, G. 2013. 12. Process views of trusting and crises. Handbook of advances in trust research. (2013), 285 .

[34] Möllering, G. 2001. The nature of trust: From Georg Simmel to a theory of expectation, interpretation and suspension. Sociology. 35, 2 (2001), 403-420.

[35] Norman, D. 2002. The design of everyday things. (2002).

[36] Olivier, P. and Wright, P. 2015. Digital civics: Taking a local turn. Interactions. 22, 4 (Jun. 2015), 61-63. DOI:https://doi.org/10.1145/2776885.

[37] Parker, S., Spires, P., Farook, F. and Mean, M. 2008. State of Trust. How to Build better Relationships between Councils and the Public. Demos, London. (2008).

[38] Ratto, M. and Ratto, M. 2017. Critical Making: Conceptual and Material Studies in Technology and Social Life Critical Making : Conceptual and Material Studies. 2243, July (2017). DOI:https://doi.org/10.1080/01972243.2011.583819.

[39] Riegelsberger, J., Sasse, M.A. and McCarthy, J.D. 2007. Trust in mediated interactions. The Oxford handbook of Internet psychology. (2007), 53-70.
[40] Roberts, N.C. 2015. The age of direct citizen participation. Routledge.

[41] Sanders, E.B.-N. and Stappers, P.J. 2008. Co-creation and the new landscapes of design. CoDesign. 4, 1 (2008), 5-18. DOI:https://doi.org/10.1080/15710880701875068.

[42] Saunders, M.N.K., Skinner, D., Dietz, G., Gillespie, N. and Lewicki, R.J. 2010. Organizational trust: $A$ cultural perspective.

[43] Taylor-Gooby, P. 2006. The efficiency/trust dilemma in public policy reform. (2006).

[44] The Aspen Institute 2019. Crisis in Democracy: Renewing Trust in America.

[45] Trope, Y. and Liberman, N. 2010. Construal-level theory of psychological distance. Psychological review. 117, 2 (2010), 440.

[46] Trump-Endorsed Brian Kemp Easily Wins GOP Runoff For Georgia Governor: NPR: 2018. https://www.npr.org/2018/07/25/632179601/trumpendorsed-brian-kemp-easily-wins-gop-runoff-forgeorgia-governor. Accessed: 2019-01-27.

[47] Tyler, T.R. 1998. Trust and democratic governance. Trust and governance. 1, (1998), 269.

[48] Urbinati, N. 2006. Representative democracy: principles and genealogy. University of Chicago Press.

[49] Uslaner, E.M. 2002. The moral foundations of trust. Cambridge University Press.

[50] Vigoda-Gadot, E. and Mizrahi, S. 2016. MANAGING DEMOCRACIES IN TURBULENT TIMES. Springer.

[51] Vlachokyriakos, V., Crivellaro, C., Le Dantec, C.A., Gordon, E., Wright, P. and Olivier, P. 2016. Digital Civics: Citizen Empowerment With and Through Technology. Proceedings of the 2016 CHI Conference Extended Abstracts on Human Factors in Computing Systems (New York, NY, USA, 2016), 1096-1099.

[52] Warren, M.E. 1999. Democracy and trust. Cambridge University Press.

[53] Welcoming Atlanta: 2015. http://www.welcomingatlanta.com/. Accessed: 201901-27.

[54] Winner, L. 1986. Do Artefacts Have Politics? The Whale and the Reactor. A Search for Limits in an Age of High Technology. (1986), 19-39. DOI:https://doi.org/10.2307/20024652.

[55] Zimmerman, J., Stolterman, E. and Forlizzi, J. 2010. An analysis and critique of Research through Design: towards a formalization of a research approach. Proceedings of the 8th ACM Conference on Designing Interactive Systems (2010), 310-319. 